\title{
Physiological predictors Of peak inspiRatory flow using Observed lung function resultS (POROS): evaluation at discharge among patients hospitalized for a COPD exacerbation
}

This article was published in the following Dove Press journal: International Journal of COPD

\author{
David B Price, ${ }^{1,2}$ Sen Yang,' \\ Simon Wan Yau Ming,' \\ Antony Hardjojo,' \\ Claudia Cabrera, ${ }^{3,4}$ \\ Andriana I Papaioannou, ${ }^{5}$ \\ Stelios Loukides, ${ }^{5}$ \\ Vicky Kritikos, ${ }^{6}$ Sinthia \\ Z Bosnic-Anticevich, ${ }^{6}$ \\ Victoria Carter, ${ }^{7}$ \\ Paul M Dorinsky \\ 'Observational and Pragmatic Research \\ Institute Pte Ltd, Singapore, Singapore; \\ ${ }^{2}$ Centre of Academic Primary Care, \\ Division of Applied Health Sciences, \\ University of Aberdeen, Aberdeen, UK; \\ ${ }^{3}$ Global Medical Affairs, AstraZeneca R \\ and D, Mölndal, Sweden; ${ }^{4}$ Department \\ of Medical Epidemiology and \\ Biostatistics, Karolinska Institute, \\ Stockholm, Sweden; ${ }^{5}$ nd Respiratory \\ Medicine Department, Medical School, \\ National and Kapodistrian University \\ of Athens, Attikon General Hospital, \\ Athens, Greece; ${ }^{6}$ Woolcock Institute \\ of Medical Research, Quality Use of \\ Respiratory Medicines Group, School \\ of Medical Sciences, University of \\ Sydney, Glebe, Australia; ${ }^{7}$ Optimum \\ Patient Care, Cambridge, UK; ${ }^{8}$ Pearl - \\ a member of the AstraZeneca Group, \\ Durham, NC, USA
}

Correspondence: David B Price Academic Primary Care, Division of Applied Health Sciences, University of Aberdeen, Polwarth Building, Foresterhill, Aberdeen AB25 2ZD, UK Tel +65 68029724

Email dprice@opri.sg
Background: Peak inspiratory flow (PIF) as generated through the resistance of a dry powder inhaler (DPI) device is a critical patient-dependent maneuver impacting the success of DPI medication delivery. Despite its importance, it is not routinely measured in clinical practice. Little is currently known about the relationship, if any, between PIF through DPI devices, routine spirometry and disease outcomes.

Aim: The aim of this study was to identify potential predictors of PIF for different DPIs from spirometric parameters and patient characteristics and explore the association between PIF and follow-up events.

Patients and methods: A retrospective observational study at discharge among patients hospitalized for a COPD exacerbation at Attikon hospital, Athens, Greece. Spirometry was performed using an Easy on-PCTM spirometer. PIF was measured through four DPI resistances using the In-Check ${ }^{\mathrm{TM}}$ DIAL. Regression analyses were used to investigate the association between PIF through resistances and spirometric parameters obtained at discharge, comorbidities and demographic parameters.

Results: Forty-seven COPD patients (mean $[ \pm \mathrm{SD}]$, age 71 [ \pm 9 ] years, $72 \%$ males, $51 \%$ current smokers) were included in this study. Overall, $85 \%$ and $15 \%$ were classified as GOLD (2017) groups D and C, respectively. Most prevalent comorbidities were hypertension (70\%) and cardiovascular disease (53\%). In the final regression model, higher PIF was significantly associated with the following: higher $\mathrm{FEV}_{1}$ and \% predicted peak expiratory flow (PEF) for Turbohaler $^{\circledR}$ ( $R$-squared value 0.374$)$; higher $\mathrm{FEV}_{1}$ and diagnosis of gastroesophageal reflux disease (GERD) for Aerolizer ${ }^{\circledR}(R$-squared value 0.209$)$ and higher $\mathrm{FEV}_{1}$, younger age and diagnosis of ischemic heart disease (IHD) for Diskus ${ }^{\circledR}$ ( $R$-squared value 0.350$)$. However, $R$-squared values for all three devices were weak $(<0.4)$.

Conclusion: The study did not provide evidence to support the use of surrogate measurements for PIF through device resistance, which could assist in determining the appropriateness of inhaler device type. Although PIF measurement is feasible in patients at discharge and could be a valuable addition to the standard of care in COPD management, it needs to be measured directly. Keywords: hospital admission, COPD, dry powder inhaler devices, inhaler technique, resistance, spirometry

\section{Introduction}

COPD is a progressive, multicomponent and complex disease. Its association with multiple comorbidities increases the overall disease burden and health care costs. ${ }^{1-3}$ 
Advanced stages of COPD are accompanied by an increasing frequency and severity of exacerbations, which accelerate the decline in lung function, decrease health status and quality of life and are a leading cause of hospitalization and mortality.,5 Management is aimed at both improving symptom control and preventing or reducing exacerbations. ${ }^{1}$

Inhaled medications are the mainstay of pharmacological treatment of COPD, allowing for the rapid delivery of small doses of medication directly to the airways and reducing the risk of adverse effects due to lower systemic exposure vs oral administration ${ }^{6,7}$ Effective inhaled treatments for COPD include bronchodilators and corticosteroids, most commonly delivered using pressurized metered dose inhalers (pMDIs) and dry powder inhalers (DPIs), each of which have different degrees of airflow resistance. ${ }^{8}$ These device types require different inhalation techniques to ensure optimal medication delivery. With pMDIs, coordination of actuation with slow and steady inspiration is required for adequate lung deposition. ${ }^{9}$ In contrast, successful drug delivery from a DPI requires an initial fast inhalation to generate sufficient peak inspiratory flow (PIF) through the device to overcome the resistance within the device and is dependent on the patient's level of effort and respiratory muscle strength. ${ }^{10,11}$ An optimal PIF which can be sustained for 2-3 seconds is needed to deaggregate drug particles and disperse the powder into finer particles suitable for lung deposition. ${ }^{10,12}$ Furthermore, the inspiratory effort required for successful drug delivery varies depending on the resistance within the DPI device. ${ }^{13}$ PIF as generated through the mouthpiece of a DPI device is a critical patient-dependent maneuver impacting the success of DPI medication delivery. ${ }^{14}$

Poor inhaler technique is common among COPD patients, ${ }^{15,16}$ with up to $68 \%$ using their inhalers incorrectly ${ }^{16}$ and nearly $30 \%$ failing to achieve a forceful inspiratory flow depending on the DPI device. ${ }^{17}$ In the CRITIKAL study, inhaler technique errors related to inspiratory effort were found to be common, and actuation before inhalation in pMDI users and insufficient inspiratory effort in DPI users were shown to be frequent critical errors associated with poor asthma outcomes. ${ }^{18}$ Inhaler misuse can also lead to reduced effectiveness of treatment, influence patient adherence to therapy and has been associated with increased health care utilization and poor COPD outcomes. ${ }^{17,19-25}$ Thus, when initiating and monitoring therapy through a DPI device, it is important to check whether a patient has the ability to inhale with sufficient inspiratory effort to use a specific DPI device so that they receive the optimal dose of medication. Despite the important role of PIF in the context of DPI technique, it is not routinely measured in clinical practice. Part of this may be due to the fact that PIF from spirometry has been used as a surrogate measure of PIF through a device, but spirometric PIF is at zero resistance and thus may be misleading. Little is currently known about the relationship, if any, between PIF through DPI devices, routine spirometry and disease outcomes.

Evidence is needed to better understand the relationship between PIF, proper device use and clinical outcomes among COPD patients. Recently, a retrospective study found that COPD patients with suboptimal PIFs that were obtained at zero resistance had fewer days to readmission after discharge for a severe exacerbation. ${ }^{26}$ In addition, while a limited number of studies have measured PIFs against different imposed resistance levels in stable COPD outpatients, ${ }^{27-32}$ and in patients at discharge following a COPD exacerbation, ${ }^{24,26,32}$ results from these studies indicate that suboptimal PIFs were prevalent in these two subgroups. Since PIF through a DPI device is not routinely measured in clinical practice, it is important to determine whether or not routine lung function tests coupled with routine demographic and clinical parameters such as severity of breathlessness and comorbidities can contribute to the prediction of PIF through a DPI or whether PIF needs to be measured directly. Finding a proxy for PIF through a DPI would be valuable in determining the appropriateness of inhaler device type and improving COPD treatment strategies.

Therefore, the present study was designed to identify whether predictors of PIF for different DPIs among inpatients at the time of discharge could be determined based on spirometric parameters and patient characteristics and to explore the association between PIF and follow-up events, including time to an exacerbation following discharge with or without hospitalization.

\section{Materials and methods Study design}

This retrospective observational study used data from patients with COPD admitted to a single hospital in Greece for a COPD exacerbation between January 2016 and September 2016. Baseline data were collected over a 1-year period prior to discharge (index date), and patients were followed until death or until April 2017 after discharge (outcome period) using primary and secondary care data. Ethical approval was obtained from the Attikon University Hospital, Chaidari, Athens, Greece (approval number 575/7-1-15). All participants gave written informed consent.

\section{Study population}

Patients were included in the study if all the following inclusion criteria were met: they had a diagnosis of COPD on 
admission to the Attikon hospital respiratory unit in Athens (Greece) based on the GOLD (2017) strategy; ${ }^{33}$ they were discharged from hospital (index date) to the community following the hospital admission for a COPD exacerbation, and they had spirometry during admission and PIFs obtained through an In-Check ${ }^{\mathrm{TM}}$ DIAL on the same day of discharge. Patients were excluded from the study if they had a diagnosis of asthma or any chronic respiratory disease other than COPD, or their PIF measurements were not obtained on the same day of discharge.

\section{Data sources}

The study used anonymized patient data from Attikon hospital, Athens, Greece. The database is a combination of electronic health records of patients admitted to hospital with a COPD-related exacerbation and prescription data obtained from a database that includes primary care prescriptions. The database includes information on diagnosis of comorbidities, lung function tests, previous medications (gathered via the national electronic prescription system), inpatient prescriptions, discharge medications, non-invasive ventilation and length of hospital stay. Post bronchodilator (PB) lung function tests were recorded in this database using a portable PC-based spirometer, the Easy on-PC ${ }^{\text {TM }}$ Spirometer (ndd Medizintechnik, Zurich, Switzerland), which meets all the American Thoracic Society/European Respiratory Society
(ATS/ERS) recommendations for diagnostic spirometers. ${ }^{34}$ Lung function tests were performed according to the ATS/ ERS 2005 guidelines. ${ }^{34}$ The data set also includes PB PIF measurements through the In-Check DIAL (Clement Clarke International Ltd., Harlow, UK), which is a portable inspiratory flow meter with an adjustable dial that can be set at zero resistance or set to simulate the resistance characteristics of common DPIs. ${ }^{35}$ It was set to simulate the following four DPI devices with varying resistance levels: low - Aerolizer ${ }^{\circledR}$ (Merck \& Co., Inc., Whitehouse Station, NJ, USA); medium/ low - Diskus ${ }^{\mathbb{B}}$ (GlaxoSmithKline plc, London, UK); medium/ high - Turbohaler ${ }^{\circledR}$ (AstraZeneca plc, London, UK or Södertälje, Sweden) and high - Handihaler ${ }^{\circledR}$ (Boehringer Ingelheim, Ingelheim, Germany). The In-Check DIAL is capable of measuring inspiratory flow rates between 0 and $120 \mathrm{~L} / \mathrm{min}$ and is calibrated with an ATS waveform generator, with a reported accuracy rate of $10 \%$ or $10 \mathrm{~L} / \mathrm{min}^{35}$

\section{Study variables}

Demographic data were collected including age (closest to the index date), gender, body mass index (BMI) (closest to the index date) and smoking status (closest to the index date) (further details and variable definitions are provided in Supplementary material S1 and Table 1). Comorbidities were recorded any time prior to the index date - as a yes/no response in the study-specific data collection form based on

Table I Unadjusted associations between spirometric parameters and PIF through each In-Check ${ }^{\text {TM }}$ DIAL resistance setting

\begin{tabular}{|c|c|c|c|}
\hline \multirow{2}{*}{$\begin{array}{l}\text { In-Check DIAL } \\
\text { resistance setting }\end{array}$} & \multirow[t]{2}{*}{ Covariates } & \multicolumn{2}{|l|}{ Simple linear regression } \\
\hline & & Unstandardized coefficient B ( $95 \% \mathrm{Cl})$ & $R$-squared statistic \\
\hline \multirow[t]{6}{*}{ Aerolizer $^{\circledR}$} & $\mathrm{FEV}_{\text {, }}$ & $18.4(2.6,34.3)$ & 0.109 \\
\hline & $\mathrm{FEV}_{\mathrm{I}} / \mathrm{FVC}$ & $20.6(-31.2,72.5)$ & 0.014 \\
\hline & $\%$ predicted FVC & $0.40(-0.09,0.89)$ & 0.056 \\
\hline & $\%$ predicted $\mathrm{FEV}_{1}$ & $0.29(-0.11,0.69)$ & 0.045 \\
\hline & $\log \left(\mathrm{FEF}_{25-75}\right)$ & $8.4(-3.5,20.3)$ & 0.046 \\
\hline & $\%$ predicted PEF & $0.47(0.10,0.84)$ & 0.133 \\
\hline \multirow[t]{6}{*}{ Diskus $^{\circledR}$} & $\mathrm{FEV}_{1}$ & $19.9(6.8,33.0)$ & 0.172 \\
\hline & $\mathrm{FEV}_{1} / \mathrm{FVC}$ & $23.7(-20.5,67.9)$ & 0.025 \\
\hline & $\%$ predicted FVC & $0.39(-0.03,0.8 I)$ & 0.071 \\
\hline & $\%$ predicted $\mathrm{FEV}_{1}$ & $0.29(-0.05,0.63)$ & 0.061 \\
\hline & $\log \left(\mathrm{FEF}_{25-75}\right)$ & $7.4(-2.6,17.4)$ & 0.050 \\
\hline & $\%$ predicted PEF & $0.41(0.09,0.74)$ & 0.134 \\
\hline \multirow[t]{6}{*}{ Turbohaler $^{\circledast}$} & $\mathrm{FEV}_{\text {, }}$ & I6.I $(7.2,24.9)$ & 0.230 \\
\hline & $\mathrm{FEV}_{1} / \mathrm{FVC}$ & $28.7(-1.4,58.8)$ & 0.076 \\
\hline & $\%$ predicted FVC & $0.39(0.11,0.67)$ & 0.151 \\
\hline & $\%$ predicted $\mathrm{FEV}$ & $0.35(0.13,0.58)$ & 0.180 \\
\hline & $\log \left(\mathrm{FEF}_{25-75}\right)$ & $9.0(2.4,15.5)$ & 0.152 \\
\hline & $\%$ predicted PEF & $0.43(0.22,0.63)$ & 0.294 \\
\hline
\end{tabular}

Note: Bold values represent significant univariate associations between spirometric parameters and PIF through each imposed resistance setting.

Abbreviations: $\mathrm{FEF}_{25-75}$, forced expiratory flow 25-75; FVC, forced vital capacity; PEF, peak expiratory flow; PIF, peak inspiratory flow. 
information from the database or patient-reported outcomes. Lung function tests were recorded every day during hospitalization (measurement closest to the day of PIF measurement was used as baseline) and included the following: $\mathrm{FEV}_{1}$; FVC; $\mathrm{FEV}_{1} / \mathrm{FVC}$; percent predicted $\mathrm{FEV}_{1}$; forced expiratory flow 25-75 $\left(\mathrm{FEF}_{25-75}\right)$ and peak expiratory flow (PEF). PIF measurements through In-Check DIAL set at different resistances were obtained by resident doctors on the day of discharge. Patients were instructed to breathe in "fast and hard" through the device following exhalation to residual volume (RV), and the best PIF out of three consecutive measurements was recorded.

The following variables were recorded 1 year prior to the index date (ie, during the baseline year): GOLD 2017 group classification; ${ }^{33}$ Modified British Medical Research Council (mMRC) score, ${ }^{33}$ Modified BORG dyspnea scale ${ }^{36}$ and type of COPD exacerbation according to Anthonisen criteria ${ }^{37}$ and exacerbation severity (variable definitions are provided in Supplementary material S1; Table 1). The following prescriptions were recorded during the baseline year from the prescription database: short-acting $\beta_{2}$ agonist (SABA) and/or short-acting muscarinic antagonist (SAMA); long-acting muscarinic antagonist (LAMA); long-acting $\beta_{2}$ agonist (LABA); inhaled corticosteroids (ICSs) and fixed dose combinations of ICS/LABA, LABA/LAMA and SABA/SAMA.

\section{Data analyses}

Summary statistics were calculated for baseline variables including mean, $\mathrm{SD}$, median, $\mathrm{IQR}$, minimum and maximum for continuous variables and counts and percentages for categorical variables. Doses of ICS containing medication were categorized into low, medium and high (Supplementary material S1; Table 2). The last recorded measurement before discharge was summarized for all lung function tests and PIFs through In-Check DIAL. Box plots were used to depict the distributions of PIF by categorical baseline variables (eg, gender, smoking status and comorbidities). Correlation matrices were used to examine the relationship between PIF through In-Check DIAL and continuous baseline variables (eg, age and spirometric parameters). This procedure was performed separately for PIF recorded through the In-Check DIAL for each resistance setting. Simple and multivariable linear regressions were used to investigate the association between PIF and spirometric parameters (individually and in combination). Multivariable linear regression was used to investigate the association between PIF and spirometric parameters and additional baseline covariates. Potential covariates were chosen based on the examination of the box plots and correlation matrices.

An exploratory analysis of the association between PIF and exacerbations following discharge was performed, and scatter plots of time to event against PIF were examined for each resistance setting. Outcomes included the following: acute exacerbation following discharge with hospitalization; acute exacerbation following discharge without hospitalization and no acute exacerbations from the time of discharge to data collection. Kaplan-Meier plots of the probability of remaining hospitalization-free following discharge for each resistance setting and by $\mathrm{PIF}$ categories $(<30$ and $\geq 30 \mathrm{~L} / \mathrm{min}$ for Handihaler; $<60$ and $\geq 60 \mathrm{~L} / \mathrm{min}$ for Aerolizer, Diskus and Turbohaler) were also examined. An exploratory analysis of time to acute exacerbation with hospitalization by baseline COPD medication (categorized by medication class) groups was also performed. The baseline medication groups were as follows: stable - patients who did not change medication; additional - those patients who received additional therapy and dropped - those patients who dropped therapy. All statistical analyses were performed using SAS version 9.4 and $\mathrm{R}$ version 3.4.0.4.

\section{Results}

\section{Patient population}

A flow diagram of the participant screening and selection process is summarized in Figure 1. The final study sample included 47 COPD patients over the study time period. The mean $( \pm \mathrm{SD})$ age of patients was $71( \pm 9)$ years with $35(75 \%)$ patients aged $\geq 65$ years, $34(72 \%)$ were male, $17(36 \%)$ had a BMI of $\geq 30$ and over half were current

Table 2 Multivariable association of spirometric parameters with PIF through each In-Check ${ }^{\mathrm{TM}}$ DIAL resistance setting

\begin{tabular}{|c|c|c|c|c|}
\hline \multirow{2}{*}{$\begin{array}{l}\text { In-Check DIAL } \\
\text { resistance setting }\end{array}$} & \multirow[t]{2}{*}{ Covariates } & \multicolumn{3}{|l|}{ Multivariable linear regression } \\
\hline & & Standardized coefficient beta $(95 \% \mathrm{Cl})$ & $R$-squared statistic & AIC \\
\hline Aerolizer $^{\circledR}$ & $\mathrm{FEV}_{1}$ & $18.0(2.6,34.3)$ & 0.109 & 289.2 \\
\hline Diskus $^{\circledR}$ & $\mathrm{FEV}_{1}$ & $19.9(6.8,33.0)$ & 0.172 & 271.3 \\
\hline \multirow[t]{2}{*}{ Turbohaler $^{\circledR}$} & $\mathrm{FEV}_{1}$ & II.8 (I.5, 22.0) & 0.374 & 216.3 \\
\hline & $\%$ predicted PEF & $0.26(0.01,0.50)$ & & \\
\hline
\end{tabular}

Abbreviations: AIC, area inside the curve; PEF, peak expiratory flow; PIF, peak inspiratory flow. 


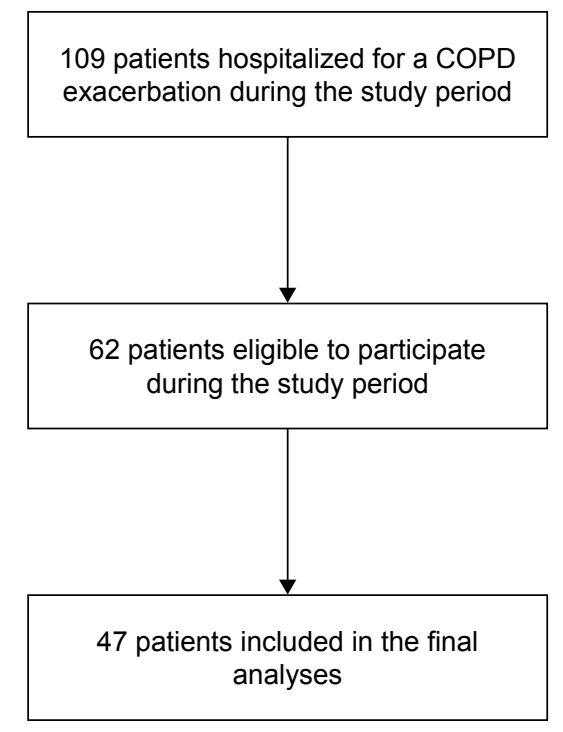

Figure I Participants' flow diagram.

smokers. The most prevalent comorbidity was hypertension $(70 \%)$, followed by cardiovascular disease (ie, heart failure, arrhythmias, stroke and pulmonary or vascular disorders) (53\%) and ischemic heart disease (IHD) (38\%) (Supplementary material S2; Table 1). The mean $( \pm \mathrm{SD})$ length of stay of index hospitalization was $8( \pm 2)$ days.

On admission to hospital, 24 (51\%) patients were categorized as being on a high dose of ICS, and on discharge, this proportion reduced to $30 \%$. The most prevalent COPD treatment combination was ICS plus a fixed dose of SABA/ SAMA (30\%), followed by a fixed dose of ICS/LABA plus LAMA (23\%) (Supplementary material S2; Table 1). Of the 47 patients, 25 (53\%) patients had stable COPD medication during the baseline year; 12 (26\%) patients were prescribed additional medications (mainly ICS) during that time; five (11\%) patients had at least one of their therapies dropped; three $(6 \%)$ patients were not receiving any treatment and two (4\%) patients had insufficient data to be categorized.
The majority of patients (89\%) were admitted to the hospital for a Type 1 exacerbation, with $40(85 \%)$ patients classified as GOLD (2017) group D and seven (15\%) as group C. Overall, 31 (70\%) patients had at least one moderate exacerbation during the baseline year. All patients had a hospitalization for a severe exacerbation during the baseline year, with $13(30 \%)$ having two or more severe exacerbations during the baseline year (Supplementary material S2; Table 2). The mean $\mathrm{FEV}_{1}$ was $39 \%$ predicted: only one (2\%) patient was classified as "mild" with an $\mathrm{FEV}_{1} \geq 80 \%$ predicted, whereas 21 (45\%) and 17 (36\%) patients had "severe" and "very severe" airflow limitation, respectively (Supplementary material S2; Table 3).

\section{Associations between spirometric parameters and PIF}

For Aerolizer, Diskus and Turbohaler, significant univariate associations were noted between $\mathrm{FEV}_{1}(R$-squared values $0.109,0.172$ and 0.230 , respectively), \% predicted PEF ( $R$-squared values $0.133,0.134$ and 0.294 , respectively) and PIF (Table 1). Additionally, for Turbohaler, significant associations were also noted between \% predicted FVC ( $R$-squared value 0.151$), \%$ predicted $\mathrm{FEV}_{1}(R$-squared value 0.180$)$ and $\log \left(\mathrm{FEF}_{25-75}\right)(R$-squared value 0.152$)$ and PIF. Despite statistical significance, the $R$-squared statistics indicate that only a small proportion of variance could be explained by the covariates (Table 1). Regression results for Handihaler are not presented as data did not allow for adequate model fit, and changing to a binary logistic regression was not possible due to small numbers in the categories.

In multivariable analysis, $\mathrm{FEV}_{1}$ was the only variable retained for Aerolizer and Diskus ( $R$-squared values 0.109 and 0.172 , respectively), whereas for Turbohaler, the best model for prediction of PIF included both $\mathrm{FEV}_{1}$ and \% predicted PEF, although the $R$-squared value (0.374)

Table 3 Multivariable association of spirometric parameters and other variables with PIF through each In-Check ${ }^{\text {TM }}$ DIAL resistance setting

\begin{tabular}{|c|c|c|c|c|}
\hline \multirow{2}{*}{$\begin{array}{l}\text { In-Check DIAL } \\
\text { resistance setting }\end{array}$} & \multirow[t]{2}{*}{ Covariates } & \multicolumn{3}{|l|}{ Multivariable linear regression } \\
\hline & & Standardized coefficient beta $(95 \% \mathrm{Cl})$ & $R$-squared statistic & AIC \\
\hline \multirow[t]{2}{*}{ Aerolizer $^{\circledast}$} & $\mathrm{FEV}_{1}$ & $17.0(1.8,32.2)$ & 0.209 & 285.6 \\
\hline & GERD & $15.6(2.3,29.0)$ & & \\
\hline \multirow[t]{3}{*}{ Diskus $^{\circledast}$} & $\mathrm{FEV}_{\text {, }}$ & $16.0(3.8,28.2)$ & 0.350 & 263.9 \\
\hline & Age & $-0.91(-1.5,-0.35)$ & & \\
\hline & IHD & $10.5(0.14,20.9)$ & & \\
\hline \multirow[t]{2}{*}{ Turbohaler ${ }^{\circledast}$} & $\mathrm{FEV}_{1}$ & II.8 (I.5, 22.0) & 0.374 & 216.3 \\
\hline & $\%$ predicted $\mathrm{PEF}$ & $0.26(0.01,0.50)$ & & \\
\hline
\end{tabular}

Abbreviations: AIC, area inside the curve; GERD, gastroesophageal reflux disease; IHD, ischemic heart disease; PEF, peak expiratory flow; PIF, peak inspiratory flow. 
was not strong (Table 2). Thus, associations between PIF and spirometric parameters were either absent or, when present, weak, indicating that routine spirometry is not adequately able to serve as a surrogate for PIF against resistance.

\section{Distributions of PIF by categorical baseline variables}

PIF distributions by categorical baseline variables showed that higher median PIFs through at least one device appeared to be associated with male gender, current smokers and a diagnosis of gastroesophageal reflux disease (GERD), osteoporosis, IHD, diabetes or GOLD group (Supplementary material S2; Figures S1-S6 and S8). In contrast, patients in the highest mMRC category appeared to have lower median PIF through Aerolizer and Diskus than those in the lower mMRC categories (Supplementary material S2; Figure S7).

\section{Correlations between PIF and continuous baseline variables}

For all resistance settings, while there was a small positive correlation between PIF and \% predicted PEF and FEV ${ }_{1}$, there was a negative correlation between PIF and age (Supplementary material S2; Figure S9A-D). Moreover, for Turbohaler only, PIF appeared to positively correlate with $\mathrm{FEF}_{25-75}, \%$ predicted $\mathrm{FEV}_{1}, \%$ predicted $\mathrm{FVC}$ and $\mathrm{FEV}_{1} /$ FVC (Supplementary material S2; Figure S9D).

\section{Associations between spirometric parameters, demographic and clinical characteristics and PIF}

For Turbohaler, the final regression model was not improved by other covariates and so included only $\mathrm{FEV}_{1}$ and \% predicted PEF ( $R$-squared value 0.374). For Aerolizer, in addition to $\mathrm{FEV}_{1}$ as a covariate, diagnosis of GERD was significantly associated with higher PIF ( $R$-squared value 0.209 ). For Diskus, the final multivariable model included $\mathrm{FEV}_{1}$, age and diagnosis of IHD ( $R$-squared value 0.350$)$. Older age was associated with lower PIF, whereas diagnosis of IHD was associated with higher PIF. However, $R$-squared values of the regression models for all three devices were weak $(<0.4)$ (Table 3$)$. Regression for Handihaler did not allow for adequate model fit and thus was not further analyzed.

\section{Associations between PIF and follow-up events}

There were no clear associations between PIF at discharge and time to acute exacerbation with hospitalization, time to acute exacerbation without a hospitalization or time free of exacerbations (Supplementary material S3; Figures S1-S3). PIFs $<60 \mathrm{~L} / \mathrm{min}$ were observed in 10 patients $(21 \%)$ for Aerolizer, 17 patients (36\%) for Diskus, 32 patients (68\%) for Turbohaler and with PIFs $<30 \mathrm{~L} / \mathrm{min}$ in six patients (13\%) for Handihaler (Supplementary material S3; Table 1). The number of patients readmitted to the hospital for acute exacerbations with $\mathrm{PIF}<60$ and $\geq 60 \mathrm{~L} / \mathrm{min}$ were as follows: for Aerolizer, 6 (13\%) and 15 (32\%), respectively; for Diskus, 9 (19\%) and 12 (26\%), respectively; for Turbohaler, $15(32 \%)$ and $6(13 \%)$, respectively, and with PIF $<30$ and $\geq 30 \mathrm{~L} / \mathrm{min}$, for Handihaler, it was 4 (9\%) and $17(36 \%)$, respectively (Supplementary material S3; Table 2). For all devices except Diskus, mean time to readmission was shorter in the higher PIF category, with Turbohaler appearing to have the largest difference in mean days to readmission (Supplementary material S3; Figure S4). For Aerolizer and Handihaler, the probability of remaining hospital-free following discharge seemed to be lower for patients with PIF $<60$ and $<30 \mathrm{~L} / \mathrm{min}$, respectively, although this was not statistically significant (Supplementary material S3; Figure S5). There was no difference in the probability of remaining hospital-free between $<60$ and $\geq 60 \mathrm{~L} / \mathrm{min}$ PIF groups for Turbohaler and Diskus. When the study sample was categorized by baseline COPD medication groups, median time to acute exacerbation with hospitalization seemed to be longest for patients who had a therapy added $(\mathrm{n}=12[29 \%])$ during the baseline year (123 days [IQR, 45-183]) and shortest for patients who had a therapy dropped (14 days [IQR, 11-53]) (Supplementary material S3; Table 3).

\section{Discussion}

This study among hospitalized COPD patients, to our knowledge, is the first to explore the relationship between PIF against DPI device resistance at the time of discharge and patient characteristics and lung function parameters as well as follow-up events. Although our study showed the feasibility of measuring PIF against DPI resistance in patients with COPD at discharge, no variable individually or in combination was useful in predicting those with low PIF against imposed resistance, suggesting that PIF against resistance needs to be measured directly.

The strength of the study lies in the fact that it is the first retrospective observational study to explore associations between a combination of baseline patient characteristics and spirometric parameters and PIFs through four different resistances corresponding to DPI devices at the time of 
discharge. The study focused on a patient cohort at discharge following hospitalization for a severe COPD exacerbation, because DPIs are often prescribed without information on PIF for this population, an often elderly population with advanced stages of COPD, high symptom burden, multi-morbidity and at greatest risk of future exacerbations. Therefore, it was important to test the feasibility of measuring PIF through imposed resistance at the time of discharge in this vulnerable population. Finally, PIF measurements were obtained at discharge against four different resistance settings from RV, which is easier and practical to perform in clinical practice than from functional residual capacity.

The study found a small positive correlation between PIF and $\mathrm{FEV}_{1}$ and $\%$ predicted PEF across all imposed resistance settings and, for three of the devices, also identified predictors of PIF though none were strong: Aerolizer $\left(\mathrm{FEV}_{1}\right.$ and diagnosis of GERD), Diskus ( $\mathrm{FEV}_{1}$, younger age and diagnosis of IHD) and Turbohaler ( $\mathrm{FEV}_{1}$ and $\%$ predicted $\mathrm{PEF}$ ). Altogether, these findings strongly suggest that PIF against device resistance needs to be measured directly.

Previous studies have also found correlations between PIF and various spirometric parameters; however, correlations between PIF through resistance and both $\mathrm{FEV}_{1}$ and $\%$ predicted $\mathrm{FEV}_{1}$ have been shown to be inconsistent, ${ }^{27,28,30,32}$ and hence, decision on inhaler device selection should not be based on FEV 1 alone. PIF and $\mathrm{FEV}_{1}$ also reflect extrapulmonary and pulmonary dynamics, respectively, and hence our findings are not surprising. PIF is a marker of inspiratory muscle strength, which can improve significantly with endurance training. ${ }^{38}$ Aging, arthritis and malnutrition can also contribute to reduced respiratory muscle strength, which reduces PIFs. ${ }^{39,40}$ Although no correlations were found between PIF and FVC in this study, reduced vital capacity has been shown to correlate with PIF in multiple studies, suggesting that other factors beyond airflow limitation, such as respiratory muscle insufficiency, hyperinflation or air trapping, may be good predictors of low PIF. 27,28,32 Although increasing age ${ }^{24,26-31}$ and female gender ${ }^{24,28,30,32}$ have consistently been shown to correlate with decreasing PIFs among COPD patients in general, no associations were found between gender and PIFs across resistances in this study. A possible explanation could be the predominance of males in our patient cohort, who have higher overall values for lung function including inspiratory mouth pressures than women ${ }^{41}$ and thus with fewer females in our cohort we detected no significant correlations between female gender and decreasing PIF. In a recent study among COPD inpatients at discharge, ${ }^{24}$ pneumonia and IHD were found to be associated with lower
PIFs through Diskus, which are inconsistent with our study findings that suggested that GERD and IHD were associated with higher PIFs using Aerolizer and Diskus, respectively. The clinical reasons for these findings are unclear and could be a reflection of confounders due to low sample size and/or multiple analysis effects. Future research studies that are adequately powered are needed to confirm our findings.

In this study, a cutoff at a PIF less than $30 \mathrm{~L} / \mathrm{min}$ for Handihaler and PIF less than $60 \mathrm{~L} / \mathrm{min}$ for Aerolizer, Diskus and Turbohaler were made in order to distinguish optimal flows from suboptimal levels based on a review of the current literature. ${ }^{42,43}$ Previous studies have measured PIF through different resistances mainly in clinically stable COPD patients and few studies have used similar cutoffs to this study. ${ }^{27-32}$ In elderly, stable COPD patients, Janssens et $\mathrm{al}^{27}$ found that among 26 patients, $12.5 \%$ had suboptimal PIF (defined as $<45 \mathrm{~L} / \mathrm{min}$ ) using Aerolizer, 20\% using Diskus and $30 \%$ using Turbohaler, whereas Mahler et $\mathrm{al}^{28}$ found that among 213 patients, 19\% had suboptimal PIF (defined as $<60 \mathrm{~L} / \mathrm{min}$ ) using Diskus. In our inpatient cohort, the prevalence of suboptimal PIF through Aerolizer, Diskus and Turbohaler at discharge was higher than that observed in a previous study of clinically stable patients with severe COPD.${ }^{27}$ This reinforces the view that COPD exacerbations can significantly reduce PIF during the acute phase as hyperinflation is prevalent and inspiratory muscle function is often compromised, ${ }^{44,45}$ and while a reduced PIF may not vary substantially during the acute exacerbation time frame, ${ }^{44}$ this reduction may continue for a few months following discharge ${ }^{32}$ Thus, PIF measurement at discharge plays a critical role in determining if an elderly patient can use or continue to use a particular DPI device, as their ability to generate sufficient inspiratory flow is often compromised following a COPD exacerbation.

This study found no strong associations between PIF through any of the resistance settings at the time of discharge and time to event outcomes. Furthermore, for all devices except for Diskus, the higher PIF group (while the lower PIF group for Diskus) appeared to have had fewer days to COPD readmission. These findings are inconsistent with those from a previous retrospective study, which found that the lower PIF group (defined as $<60 \mathrm{~L} / \mathrm{min}$ against zero resistance) had significantly fewer days to COPD readmission and that PIF was the only significant variable associated with readmission. ${ }^{26}$ Additionally, our results seem to suggest that patients with Aerolizer PIF $<60 \mathrm{~L} / \mathrm{min}$ and patients with Handihaler $\mathrm{PIF}<30 \mathrm{~L} / \mathrm{min}$ have a higher probability of being readmitted for an acute exacerbation. It is possible that our results could 
be confounded by the very small sample size and that some patients were either not using ICS or using low-dose ICS on admission and a greater proportion were using moderate-to high-dose ICS at discharge, suggesting that the initial event may have been a consequence of undertreatment.

\section{Limitations}

There are some limitations to this study, which could affect the generalizability of the results. The retrospective design of the study, and the setting of a single hospital, meant that the final sample size was small, which could explain the weak association between PIF and follow-up events. Furthermore, as this observational study was conducted under conditions of real-life clinical practice, it meant that all lung function tests including PIFs among hospitalized COPD patients were performed post bronchodilation, which may have further weakened the association between PIF and follow-up events. Another limitation of the study is the multiple analysis effect, where up to $5 \%$ of the comparisons could yield positive results by chance alone, and therefore some unexplained results may have been only by chance. Finally, while our study was able to determine additional "class" of therapy taken during the baseline year, it was not possible to determine after discharge whether additional drug delivery devices (eg, nebulizers, spacers) were being used, and/or inhaler technique training, smoking cessation or pulmonary rehabilitation (endurance training) had been undertaken, as these factors could potentially affect follow-up events. Nevertheless, this research could not identify any strong predictors of PIF for different DPIs among inpatients at the time of discharge, suggesting that PIF against resistance needs to be measured directly. PIF measured against resistance in the clinical setting can be a useful tool to guide treatment options for a COPD population at greatest risk of future adverse outcomes. Measurement of PIF against resistance may not only help to personalize device selection (pMDI vs DPI) and even DPI selection but may also help to identify patients with reduced PIFs who could benefit from either pulmonary rehabilitation programs that focus on improving inspiratory muscle strength leading to increased PIF and thus better drug delivery or from dual bronchodilation in addition to ICS, which may help to improve inspiratory capacity and thus PIF.

\section{Conclusion}

The results of this study have important clinical implications. First, this study did not provide strong evidence to support the use of surrogate measurements for PIF through device resistance, which could assist in selecting appropriate inhaler devices in patients with COPD. Although PIF measurement against resistance would be a valuable addition to the standard of care in the management of COPD, it needs to be measured directly. Second, this study showed the feasibility of measuring PIF against resistance in patients with COPD at discharge. Further studies are needed to define the impact of PIF, device selection and outcomes after discharge following a COPD exacerbation.

\section{Acknowledgments}

This study was supported by AstraZeneca. The abstract of this paper was presented at the American Thoracic Society International Conference 2017 as a poster presentation with interim findings.

\section{Disclosure}

David B Price has board membership with Aerocrine, Amgen, AstraZeneca, Boehringer Ingelheim, Chiesi, Mylan, Mundipharma, Napp, Novartis, Regeneron Pharmaceuticals, Sanofi Genzyme, Teva Pharmaceuticals; consultancy agreements with Almirall, Amgen, AstraZeneca, Boehringer Ingelheim, Chiesi, GlaxoSmithKline, Mylan, Mundipharma, Napp, Novartis, Pfizer, Teva Pharmaceuticals, Theravance; grants and unrestricted funding for investigator-initiated studies (conducted through Observational and Pragmatic Research Institute Pte Ltd) from Aerocrine, AKL Research and Development Ltd, AstraZeneca, Boehringer Ingelheim, British Lung Foundation, Chiesi, Mylan, Mundipharma, Napp, Novartis, Pfizer, Regeneron Pharmaceuticals, Respiratory Effectiveness Group, Sanofi Genzyme, Teva Pharmaceuticals, Theravance, UK National Health Service, Zentiva (Sanofi Generics); payment for lectures/speaking engagements from Almirall, AstraZeneca, Boehringer Ingelheim, Chiesi, Cipla, GlaxoSmithKline, Kyorin, Mylan, Merck, Mundipharma, Novartis, Pfizer, Regeneron Pharmaceuticals, Sanofi Genzyme, Skyepharma, Teva Pharmaceuticals; payment for manuscript preparation from Mundipharma, Teva Pharmaceuticals; payment for the development of educational materials from Mundipharma, Novartis; payment for travel/accommodation/meeting expenses from Aerocrine, AstraZeneca, Boehringer Ingelheim, Mundipharma, Napp, Novartis, Teva Pharmaceuticals; funding for patient enrolment or completion of research from Chiesi, Novartis, Teva Pharmaceuticals, Zentiva (Sanofi Generics); stock/stock options from AKL Research and Development Ltd which produces phytopharmaceuticals; owns $74 \%$ of the social enterprise Optimum Patient Care Ltd (Australia and UK) and $74 \%$ of Observational and Pragmatic Research Institute Pte 
Ltd (Singapore); and is peer reviewer for grant committees of the Efficacy and Mechanism Evaluation programme, and Health Technology Assessment. David B Price is owner and managing director of Observational and Pragmatic Research Institute Pte Ltd. Vicky Kritikos has received honoraria from AstraZeneca, GlaxoSmithKline and Pfizer. Sinthia Z Bosnic-Anticevich has received honoraria from AstraZeneca, Boehringer Ingelheim, GlaxoSmithKline, Mundipharma and Teva Pharmaceuticals for her contribution to advisory boards/ key international expert forum. Victoria Carter, Sen Yang, Antony Hardjojo and Simon Wan Yau Ming are employees of the Observational and Pragmatic Research Institute Pte Ltd, which has conducted paid research in respiratory disease on behalf of the following organizations in the past 5 years: Anaxys, AstraZeneca, Boehringer Ingelheim, British Lung Foundation, Chiesi, Circassia (formerly Aerocrine), GlaxoSmithKline, Harvey Walsh, Mapi, Morningside Healthcare, Mundipharma, Mylan (formerly Meda), Napp, Novartis, Orion, Plymouth University, Regeneron, Respiratory Effectiveness Group, Roche, Sanofi, Takeda, Teva, University of East Anglia, Zentiva (a Sanofi company). Paul M Dorinsky is an employee of Pearl - a member of the AstraZeneca Group. Claudia Cabrera is an employee of AstraZeneca. Andriana I Papaioannou and Stelios Loukides declare no relevant conflicts of interest. The authors report no other conflicts of interest in this work.

\section{References}

1. Global Initiative for Chronic Obstructive Lung Disease [homepage on the Internet]. From the Global Strategy for the Diagnosis, Management and Prevention of COPD, Global Initiative for Chronic Obstructive Lung Disease (GOLD). 2018 Report. Available from: www.goldcopd. org. Accessed January 2, 2018.

2. Barnes PJ. Immunology of asthma and chronic obstructive pulmonary disease. Nat Rev Immunol. 2008;8(3):183-192.

3. Choudhury G, Rabinovich R, Macnee W. Comorbidities and systemic effects of chronic obstructive pulmonary disease. Clin Chest Med.2014; 35(1):101-130.

4. Corlateanu A, Covantev S, Mathioudakis AG, Botnaru V, Siafakas N. Prevalence and burden of comorbidities in Chronic Obstructive Pulmonary Disease. Respir Investig. 2016;54(6):387-396.

5. Agustí A, Calverley PM, Decramer M, Stockley RA, Wedzicha JA. Prevention of exacerbations in chronic obstructive pulmonary disease: knowns and unknowns. Chronic Obstr Pulm Dis. 2014;1(2): 166-184.

6. Vincken W, Dekhuijzen PR, Barnes P; ADMIT Group. The ADMIT series - Issues in inhalation therapy. 4) How to choose inhaler devices for the treatment of COPD. Prim Care Respir J. 2010;19(1): $10-20$.

7. Lavorini F. Inhaled drug delivery in the hands of the patient. J Aerosol Med Pulm Drug Deliv. 2014;27(6):414-418.

8. Lavorini F, Corrigan CJ, Barnes PJ. Aerosol drug management improvement team. Retail sales of inhalation devices in European countries: so much for a global policy. Respir Med. 2011;105:1099-1103.

9. Laube BL, Janssens HM, de Jongh FH, et al. What the pulmonary specialist should know about the new inhalation therapies. Eur Respir J. 2011;37(6):1308-1417.
10. Chrystyn H. Is inhalation rate important for a dry powder inhaler? Using the In-Check Dial to identify these rates. Respir Med. 2003;97(2): 181-187.

11. Sanchis J, Corrigan C, Levy ML, Viejo JL; ADMIT Group. Inhaler devices - from theory to practice. Respir Med. 2013;107(4): 495-502.

12. Azouz W, Chrystyn H. Clarifying the dilemmas about inhalation techniques for dry powder inhalers: integrating science with clinical practice. Prim Care Respir J. 2012;21(2):208-213.

13. Lavorini F, Mannini C, Chellini E, Fontana GA. Optimising inhaled pharmacotherapy for elderly patients with chronic obstructive pulmonary disease: the importance of delivery devices. Drugs Aging. 2016; 33(7):461-473.

14. Rogliani P, Calzetta L, Coppola A, et al. Optimizing drug delivery in COPD: The role of inhaler devices. Respir Med. 2017;124:6-14.

15. Lavorini F, Magnan A, Dubus JC, et al. Effect of incorrect use of dry powder inhalers on management of patients with asthma and COPD. Respir Med. 2008;102(4):593-604.

16. Melzer AC, Ghassemieh BJ, Gillespie SE, et al. Patient characteristics associated with poor inhaler technique among a cohort of patients with COPD. Respir Med. 2017;123:124-130.

17. Melani AS, Bonavia M, Cilenti V. On behalf of the Gruppo Educazionale Associazione Italiana Pneumologi Ospedalieri (AIPO). Inhaler mishandling remains common in real life and is associated with reduced disease control. Respir Med. 2011;105:930-938.

18. Price DB, Román-Rodríguez M, Mcqueen RB, et al. Inhaler errors in the CRITIKAL study: type, frequency, and association with asthma outcomes. J Allergy Clin Immunol Pract. 2017;5(4):1071-1081.

19. Sanchis J, Gich I, Pedersen S. On behalf of the Aerosol Drug Management Improvement Team (ADMIT). Systematic review of errors in inhaler use: has patient technique improved over time? Chest. 2016; 150(2):394-406.

20. Chrystyn H, Price DB, Molimard M, et al. Comparison of serious inhaler technique errors made by device-naïve patients using three different dry powder inhalers: a randomised, crossover, open-label study. $B M C$ Pulm Med. 2016;16:12.

21. Braido F, Chrystyn H, Baiardini I, et al. "Trying, But Failing" - The Role of Inhaler Technique and Mode of Delivery in Respiratory Medication Adherence. J Allergy Clin Immunol Pract. 2016;4(5): 823-832.

22. Price D, Keininger DL, Viswanad B, Gasser M, Walda S, Gutzwiller FS. Factors associated with appropriate inhaler use in patients with COPD lessons from the REAL survey. Int J COPD. 2018;13:695-702.

23. Vrijens B, Dima AL, van Ganse E, et al. What we mean when we talk about adherence in respiratory medicine. J Allergy Clin Immunol Pract. 2016;4(5):802-812.

24. Sharma G, Mahler DA, Mayorga VM, Deering KL, Harshaw O, Ganapathy V. Prevalence of low peak inspiratory flow rate at discharge in patients hospitalized for COPD exacerbation. Chronic Obstr Pulm Dis. 2017;4(3):217-224.

25. Molimard M, Raherison C, Lignot S, et al. Chronic obstructive pulmonary disease exacerbation and inhaler device handling: real-life assessment of 2935 patients. Eur Respir J. 2017;49(2):1601794.

26. Loh CH, Peters SP, Lovings TM, Ohar JA. Suboptimal inspiratory flow rates are associated with chronic obstructive pulmonary disease and all-cause readmissions. Ann Am Thorac Soc. 2017;14(8): 1305-1311.

27. Janssens $W$, Vandenbrande $P$, Hardeman E, et al. Inspiratory flow rates at different levels of resistance in elderly COPD patients. Eur Respir J. 2008;31(1):78-83.

28. Mahler DA, Waterman LA, Gifford AH. Prevalence and COPD phenotype for a suboptimal peak inspiratory flow rate against the simulated resistance of the Diskus ${ }^{\circledR}$ dry powder inhaler. J Aerosol Med Pulm Drug Deliv. 2013;26(3):174-179.

29. Kawamatawong T, Khiawwan S, Pornsuriyasak P. Peak inspiratory flow rate measurement by using In-Check DIAL for the different inhaler devices in elderly with obstructive airway diseases. $J$ Asthma Allergy. 2017;10:17-21. 
30. Malmberg LP, Rytilä P, Happonen P, Haahtela T. Inspiratory flows through dry powder inhaler in chronic obstructive pulmonary disease: age and gender rather than severity matters. Int $J$ Chron Obstruct Pulmon Dis. 2010;5:257-262.

31. Seheult JN, Costello S, Tee KC, et al. Investigating the relationship between peak inspiratory flow rate and volume of inhalation from a Diskus $^{\mathrm{TM}}$ Inhaler and baseline spirometric parameters: a cross-sectional study. Springerplus. 2014;3(496):496.

32. van der Palen J. Peak inspiratory flow through diskus and turbuhaler, measured by means of a peak inspiratory flow meter (In-Check DIAL). Respir Med. 2003;97(3):285-289.

33. Global Initiative for Chronic Obstructive Lung Disease [homepage on the Internet]. From the Global Strategy for the Diagnosis, Management and Prevention of COPD, Global Initiative for Chronic Obstructive Lung Disease (2017 Report). Available from: www.goldcopd.org. Accessed January 2, 2018.

34. Miller MR, Hankinson J, Brusasco V, et al. Standardisation of spirometry. Eur Respir J. 2005;26(2):319-338.

35. Alliance Tech Medical [homepage on the Internet]: In-Check inspiratory flow measurement device. Available from: http://www.alliancetechmedical.com/products/check-inspiratory-flow-measurement-device/. Accessed January 2, 2018.

36. Kendrick KR, Baxi SC, Smith RM. Usefulness of the modified 0-10 Borg scale in assessing the degree of dyspnea in patients with COPD and asthma. J Emerg Nurs. 2000;26(3):216-222.

37. Anthonisen NR, Manfreda J, Warren CP, Hershfield ES, Harding GK, Nelson NA. Antibiotic therapy in exacerbations of chronic obstructive pulmonary disease. Ann Intern Med. 1987;106(2):196-204.
38. Chen R, Chen R, Chen X, Chen L. Effect of endurance training on expiratory flow limitation and dynamic hyperinflation in patients with stable chronic obstructive pulmonary disease. Intern Med J. 2014; 44(8):791-800.

39. Jarvis S, Ind PW, Shiner RJ. Inhaled therapy in elderly COPD patients; time for re-evaluation? Age Ageing. 2007;36(2):213-218.

40. Franssen FM, Wouters EF, Schols AM. The contribution of starvation, deconditioning and ageing to the observed alterations in peripheral skeletal muscle in chronic organ diseases. Clin Nutr. 2002;21(1):1-14.

41. Enright PL, Kronmal RA, Manolio TA, Schenker MB, Hyatt RE. Respiratory muscle strength in the elderly. Correlates and reference values. Cardiovascular Health Study Research Group. Am J Respir Crit Care Med. 1994;149(2 Pt 1):430-438.

42. Demoly P, Hagedoorn P, de Boer AH, Frijlink HW. The clinical relevance of dry powder inhaler performance for drug delivery. Respir Med. 2014;108(8):1195-1203.

43. Ghosh S, Ohar JA, Drummond MB. Peak inspiratory flow rate in chronic obstructive pulmonary disease: implications for dry powder inhalers. J Aerosol Med Pulm Drug Deliv. 2017;30(6):381-387.

44. Levine S, Kaiser L, Leferovich J, Tikunov B. Cellular adaptations in the diaphragm in chronic obstructive pulmonary disease. $N$ Engl J Med. 1997;337(25):1799-1806.

45. Gosselink R, Troosters T, Decramer M. Distribution of muscle weakness in patients with stable chronic obstructive pulmonary disease. J Cardiopulm Rehabil. 2000;20(6):353-360.
International Journal of COPD

\section{Publish your work in this journal}

The International Journal of COPD is an international, peer-reviewed journal of therapeutics and pharmacology focusing on concise rapid reporting of clinical studies and reviews in COPD. Special focus is given to the pathophysiological processes underlying the disease, intervention programs, patient focused education, and self management protocols.

\section{Dovepress}

This journal is indexed on PubMed Central, MedLine and CAS. The manuscript management system is completely online and includes a very quick and fair peer-review system, which is all easy to use. Visit http://www.dovepress.com/testimonials.php to read real quotes from published authors. 